\title{
Willingness-to-pay for predictive tests with no immediate treatment implications: A survey of US residents
}

Article in Health Economics · March 2012

DOI: 10.1002/hec.1704 · Source: PubMed

CITATIONS

52

7 authors, including:

Peter Neumann

Tufts Medical Center

386 PUBLICATIONS $\quad 10,348$ CITATIONS

SEE PROFILE

Thomas W Concannon

RAND Corporation

28 PUBLICATIONS 395 CITATIONS

SEE PROFILE
READS

164
Joshua T Cohen

Tufts Medical Center

144 PUBLICATIONS 2,627 CITATIONS

SEE PROFILE

David Kent

Tufts Medical Center

180 PUBLICATIONS 3,861 CITATIONS

SEE PROFILE 


\title{
WILLINGNESS TO PAY FOR PREDICTIVE TESTS WITH NO IMMEDIATE TREATMENT IMPLICATIONS: A SURVEY OF U.S. RESIDENTS
}

\author{
Peter J. Neumann ${ }^{1,2,6}$, Joshua T. Cohen ${ }^{1,6}$, James K. Hammitt ${ }^{3,5}$, Thomas W. Concannon ${ }^{2,4,6}$, \\ Hannah R. Auerbach ${ }^{1}$, ChiHui Fang ${ }^{1}$, David M. Kent ${ }^{2,4}$ \\ ${ }^{1}$ Center for the Evaluation of Value and Risk in Health, Institute for Clinical Research and \\ Health Policy Studies, Tufts Medical Center \\ ${ }^{2}$ Tufts Clinical and Translational Science Institute \\ ${ }^{3}$ Harvard University (Center for Risk Analysis) \\ ${ }^{4}$ Institute for Clinical Research and Health Policy Studies, Tufts Medical Center \\ ${ }^{5}$ Toulouse School of Economics (LERNA-INRA) \\ ${ }^{6}$ Tufts University School of Medicine
}

September 2010

Funding Source: This research was supported by a grant from the InHealth Foundation.

Corresponding Author:

Peter J. Neumann, Sc.D.

Director, Center for the Evaluation of Value \& Risk in Health, Professor, Tufts University School of Medicine

Institute for Clinical Research and Health Policy Studies

800 Washington St., Tufts Medical Center, \#063

Boston, MA 02111

Tel: (617) 636-2335; Fax: (617) 636-5560

Email: pneumann@tuftsmedicalcenter.org 


\title{
WILLINGNESS TO PAY FOR PREDICTIVE TESTS WITH NO IMMEDIATE TREATMETN IMPLICATIONS: A SURVEY OF U.S. RESIDENTS
}

Keywords: willingness to pay, predictive tests, Alzheimer's disease, cancer, arthritis

\begin{abstract}
We assessed how much, if anything, people would pay for a laboratory test that predicted their future disease status. A questionnaire was administered via an internet-based survey to a random sample of adult U.S. respondents. Each respondent answered questions about two different scenarios, each of which specified: one of four randomly selected diseases (Alzheimer's, arthritis, breast cancer, or prostate cancer); an ex ante risk of developing the disease (randomly designated $10 \%$ or $25 \%$ ); and test accuracy (randomly designated perfect or "not perfectly accurate"). Willingness to pay (WTP) was elicited with a double-bounded, dichotomous-choice approach. Of 2,223 respondents who completed the survey, most (70-88\%, depending on the scenario) were inclined to take the test. WTP was lower for Alzheimer's and higher for prostate cancer compared with arthritis, and rose somewhat with disease prevalence and for the perfect vs. imperfect test. Median WTP varied from \$109 for the imperfect arthritis test to \$263 for the perfect prostate cancer test. Respondents' preferences for predictive testing, even in the absence of direct treatment consequences, reflected health and non-health related factors, and suggests that conventional cost-effectiveness analyses may underestimate the value of testing.
\end{abstract}


Predictive testing is one of the fastest growing areas of health care,(National Imaging Associates, 2008;Knechtges, 2007;PricewaterhouseCoopers, 2006) its growth spurred by technological advances that promise more accurate analysis of a patient's disease and prognosis, and the prospect of better care management.(Chan 2002;Hillman et al. 2005;Iglehart 2006; Maitino et al. 2003;Seshadri 2005) New applications have emerged for diseases from Alzheimer’s to cancer to endocrine disorders.(Bossuyt, Verweire, \& Blanckaert 2007;Cooke 2002;Kolata 2008) However, increased spending has led payers to ask more demanding questions about whether benefits of new tests are worth their costs and, if so, in what situations.

Economic evaluation of test information has typically relied on conventional methods of decision analysis and cost-effectiveness analysis.(Weinstein et al. 1980) Consensus panels have recommended quantifying health benefits using quality-adjusted life years (QALYs) that reflect changes in both longevity and quality of life, with "quality of life" quantified in a way that is consistent with preferences people have for different health states.(Singer \& Applegate 2001; Weinstein et al. 1996) Published cost-utility analyses pertaining to in vitro or laboratory diagnostics increased from 1.8 per year in the 1990s to 13.4 annually between 2000 and 2008.(Tufts Medical Center 2010)

In this conventional framework, test information is valued only to the extent that it leads individuals and their agents to make better medical decisions.(Baker, Atlas, \& Afendulis 2008;Grosse, Wordsworth, \& Payne 2008) In practice, however, patients may value information from a test even when the information does not affect treatment.(Lee, Neumann, \& Rizzo 2009) For example, test information may provide reassurance to patients and physicians that serious disease is absent,(Blackmore et al. 1999;Hillman, Amis, Weinreb, \& Neiman 2005) especially 
for those identified as at risk.(Asch, Patton, \& Hershey 1990;Kenen 1996) A new test may be valuable because it provides quicker access to such information.(Baker, Atlas, \& Afendulis 2008) In addition, research also shows that people dislike uncertainty(Shogren 2005;Viscusi, Magat, \& Huber 1991) and so may prefer situations in which they have better information about their health or about their chances of developing a condition.(Ellsberg 1961)

Test information may be useful in both medical and non-medical decision making. For diseases that are treatable, such information is needed to guide medical treatment choices. Even for diseases that cannot be treated, test information may be helpful for non-medical decision making. For example, a patient who learns he has developed a life-threatening but untreatable disease may choose to use remaining time for travel or family engagements. Similarly, the patient might choose to alter employment, savings or other financial plans. Of course, test information may also induce harms unrelated to treatment consequences. The experience of being tested itself can cause anxiety and discomfort for patients.(Gyrd-Hansen \& Rasmussen 1972)

Contingent valuation (CV) or willingness to pay (WTP) surveys offer researchers substantial flexibility to investigate the value of a wide range of health and non-health benefits resulting from predictive tests. The WTP literature in health care has grown over the past few decades, with applications to different disease areas, treatment modalities, and survey methods (Blumenschein \& Johannesson 1999;Diener, O'Brien, \& Gafni 1998;Lachaine 2006;Olsen \& Smith 2001;Rodriguez-Monguio, Otero, \& Rovira 2003;Sach, Smith, \& Whynes 2007). Several dozen WTP studies on a range of diagnostic and predictive tests have been published in a variety of clinical areas and modalities.(Appel et al. 1990;Berwick \& Weinstein 1985;Brooks et al. 2005; Carlos et al. 2002;Caughey et al. 2004;Cho et al. 2000;Donaldson et al. 1995;Fauli \& Thue 
2008;Frew, Wolstenholme, \& Whynes 2001;Hirth et al. 1999;Hirth et al. 2000;Lata, Binkley, \& Elliott 2002;Liang et al. 2003;Miedzybrodzka et al. 1995;Mushlin et al. 1994b;Mushlin et al. 2005;Neumann et al. 2001;Papatheofanis 1998;Papatheofanis 2000;Phillips et al. 2006;Raab et al. 2002;Ryan et al. 2005;Salkeld et al. 2003;Schiffner et al. 2003;Shih et al. 2007;Tarasiuk et al. 2003;Wagner et al. 2001; Whynes, Frew, \& Wolstenholme 2003;Wordsworth, Ryan, \& Waugh 2001; Yasunaga et al. 2006a; Yasunaga et al. 2006b;Yasunaga et al. 2007;Yasunaga 2008) They have generally found that people have positive WTP for test information, even in the absence of treatment consequences. However, most of the studies relied on small convenience samples. Moreover, they vary considerably with respect to the methods they use to estimate WTP.

We conducted a population-based survey to investigate people's willingness to pay for predictive testing. We assessed whether and how much people would pay for a predictive laboratory test under conditions in which the test information had no immediate treatment implications. We also examined how preferences varied with disease type, disease prevalence, and test accuracy.

\section{DATA AND METHODS}

\subsection{Survey design}

We presented respondents with hypothetical scenarios in which they were asked to imagine that in the course of a regular check up, their physician told them they were healthy, but that someone their age had a chance (e.g., 25\%) of one day contracting a particular disease (e.g., Alzheimer's) (Figure 1). Respondents were told that the doctor mentioned a new blood test that would tell respondents whether or not they would one day develop the disease. Patients would have to pay for the test themselves, however, because insurance did not cover it. 
Respondents were told to assume that they could not prevent the disease from occurring, but that for people who eventually acquired the disease, treatments were available that might help. The scenario stated at the outset that questions were based on hypothetical or imaginary situations and that responses were confidential. The questionnaire included a pictogram illustrating the disease risk.

Willingness to pay for the test was elicited using a double-bounded, dichotomous-choice approach, which presented respondents with a binary (yes/no) bidding game, with respondents randomized to one of several initial starting bids (\$50, \$150, \$300, \$500).(Hanemann, Loomis, \& Kanninen 1991) Respondents answering “yes" to the first question were asked if they would pay twice the initial price. Respondents answering "no" were asked if they would pay half the initial price. If the second response was "no," the subject was asked if they would be willing to take the test for free.

This bidding-game format is believed to produce less biased responses than open-ended and payment-card formats, because respondents have no incentive to misrepresent their preferences.(Hanemann, Loomis, \& Kanninen 1991) A survey using this format elicits the respondent's upper and lower bounds on their willingness to pay, determined by the smallest bid to which they respond "no" and the largest bid to which they respond "yes" (the lower bound is assumed to be zero for respondents who answer "no" to both questions, and the upper bound is undefined for those who answer "yes" to both). By presenting this series of questions to many respondents, it is possible to estimate the distribution of willingness to pay for the test.

Each respondent answered questions about two different disease scenarios, each of which specified one of four randomly selected diseases: Alzheimer's disease, arthritis, breast cancer (female respondents only), and prostate cancer (male respondents only). Each scenario also 
specified an ex ante risk of developing the disease in the future (randomly designated either 10\% or $25 \%$ ), and about test accuracy (randomly designated perfect or "not perfectly accurate"). Figure 2 illustrates the survey design and details the number of respondents randomized to each scenario.

We asked respondents who answered 'YES' to either the first or second bid question to select from multiple options what actions they would take if the test reported they would develop disease (e.g., get their finances in order). We also asked respondents about whom they would tell in the event of a positive test result, and how worried they would be that others (e.g., their employer) would gain access to the test information. Finally, we elicited information on demographic/socio-economic information, health status (personal history related to the health conditions described in the test scenarios), and a series of questions on risk attitudes (e.g., do you wear a seatbelt?). The survey instrument is available from the authors upon request.

\section{$2.2 \quad$ Fielding the survey}

The questionnaire was administered via the internet to a national panel of adult U.S. residents maintained by a survey research firm, Knowledge Networks (Menlo Park, California). Panel members are recruited using probability sampling and Knowledge Networks maintains various procedures to achieve sample representativeness and to prevent self-selection bias (J.Michael Dennis 2010). The survey panels resemble US Census benchmarks for primary demographics. Panelists were selected at random to receive an e-mail invitation to the survey. To prevent respondents from completing the survey more than once, each invitation contained a unique password. Reminder invitations were sent out at 2-4 day intervals to improve response rates. 
A sample of 4,262 panelists was drawn from the weighted Knowledge Networks panel using probability proportional to size (PPS) sampling methods; 1,906 responded to the invitation and qualified for the study, yielding a total of 1,837 completed surveys. (Of these, 1,463 responded to the WTP questions reported on in this paper; the remainder were randomly assigned to questions about other topics that are not included in this analysis.) The survey was pre-tested on 29 respondents and pilot-tested on a sample of 193 respondents to assess the clarity of wording, to verify proper question branching and skip patterns, and to test the appropriateness of the starting bids. Specifically, we conducted an initial pretest with 29 cases using $\$ 50 / \$ 100$ as the initial bids. Because a relatively high percentage of respondents were willing to pay for the test at these levels, we used $\$ 50 / \$ 500$ as the initial bids for the follow-up pilot test of 386 cases. Pilot-test results suggested these values reasonably captured the WTP distribution and so we used $\$ 50 / \$ 150 / \$ 300 / \$ 500$ as the initial bids in the main study. Because the pilot test revealed no problems with the questionnaire, we included these respondents in the final analyses. We excluded respondents who stated they had ever been diagnosed with any of four diseases studied. The survey required approximately 15 minutes to complete.

\subsection{Analysis}

The double-bounded, dichotomous-choice format permits an analysis of the willingnessto-pay data as a survival analysis with censoring.(Hanemann, Loomis, \& Kanninen 1991) Although a respondent's exact WTP is not observed, it is assumed to lie above any bid amount to which she replied "yes" and below any bid amount to which she replied "no".

We implemented a two-part model to estimate WTP.(Hammitt \& Zhou 2006) The first model component used logistic regression (proc LOGISTIC, SAS version 9.2, Cary, NC) to estimate the probability that WTP $>0$. We assumed WTP to be zero if the respondent rejected 
the two bids offered and answered "no" to the follow up question asking if the respondent would take the test for free. Other respondents were assumed to have a non-zero WTP with bounds determined by their responses to the bid questions.

The second model component limited attention to respondents with WTP $>0$. We used maximum likelihood regression (SAS proc LIFEREG) to estimate median and mean WTP values for these respondents assuming WTP followed a lognormal distribution.

We conducted two sets of regressions to predict WTP. The first set included our main predictors of WTP, namely disease type (four values), prior disease risk (two values), and test accuracy (two values). We estimated the median WTP for the complete population (zero and non-zero respondents) to be the $50-p$ percentile of the WTP distribution for the non-zero respondents, where $p$ is the percent of the population with zero WTP. We computed mean WTP as the product of $(1-p)$ and the arithmetic mean WTP for non-zero respondents.

We conducted a second set of regression analyses to determine if other factors influenced WTP. This set incorporated main predictors for WTP from the first analysis as well as several adjusters, including log income (continuous), education (four categories), gender, and age (continuous). We added these independent variables to test the credibility of the survey (e.g., WTP should increase with income and test accuracy) and to learn something about how WTP varies with individual characteristics (e.g., sociodemographic variables and respondent attitudes). We also calculated and included in the regression a "risk score," which is an aggregation of responses to questions indicative of respondent risk tolerance. Its value is the sum of points awarded based on responses to each of five questions (e.g., do you were a seatbelt?) (see footnote to Table 1). 


\section{RESULTS}

Table 1 reports sample statistics. Table 2 reports the proportion of respondents who would take the test (including those who would take it only if it were free), and the mean and median WTP for all respondents, including those who would not take the test even if it were free. A majority of respondents were inclined to take the predictive test across all diseases and scenarios, with proportions varying from $70 \%$ to $88 \%$. Inclination to take the test was highest for prostate cancer (85-88\%, depending on disease risk and test accuracy) and lowest for Alzheimer's disease (70-75\%). A higher ex ante risk of disease (25\% vs. 10\%) was associated with a somewhat higher WTP, and WTP was somewhat higher for the perfect than the imperfect test. Mean WTP ranged from $\$ 320$ for an imperfect arthritis test to $\$ 622$ for an perfect prostrate cancer test.

Table 3 presents the multivariate regression results. We present the impact on the probability that subjects are inclined to take the test and the impact of various characteristics on the natural log of the geometric mean WTP among these subjects. Respondents who would take the test include those who were willing to pay for testing as well as those who would take it if it were free. We present a "simple" model, which contains the disease type, disease risk, and test accuracy, and an "expanded" model, which also includes income, education, gender, age, and risk score. The proportion of respondents inclined to take the test was significantly smaller for Alzheimer's and higher for prostate cancer than for arthritis. This proportion was also significantly higher for the perfect than the imperfect test. Older respondents, females, those with a bachelor's degree or higher, and those with a lower risk score (i.e., exhibiting less risk taking behavior) were significantly less likely to want the test even if it were free. 
Restricting attention to only those respondents inclined to take the test, willingness to pay was significantly higher for breast cancer, Alzheimer's and prostate cancer than for arthritis. WTP rose with income and was lower for females and those with lower risk scores.

Regarding what they would do with a positive test, respondents most frequently stated that they were very likely or somewhat likely to obtain a second medical opinion (59\%) or seek medical care from a medical specialist (59\%) (responses were not mutually exclusive) (Table 4). Other popular responses included signing an advance directive document (51\%), spending more time with family (51\%), getting finances in order (48\%), and traveling more (31\%). Frequencies were considerably higher for the Alzheimer’s disease and cancer scenarios than for arthritis. Less common responses were seeking help from a medical professional (27\%), changing jobs (7\%), and quitting work (7\%).

Asked whom they would tell if they received a positive test, respondents most often stated they would definitely or probably tell their spouse (69\%), other family members or relatives (55\%), close friends (50\%), or children (49\%) (Table 4). Fewer would tell their clergy member (34\%) or co-workers (22\%). Percentages were generally lower for the Alzheimer's scenario. In terms of concerns about people gaining access to the information, respondents worried most about insurance companies (37\%), followed by the government (28\%), and their employers (24\%). Concerns were highest for Alzheimer’s relative to other diseases. 


\section{DISCUSSION}

\subsection{Preferences for predictive testing}

Observers have long argued that conventional techniques of economic evaluation may insufficiently capture the value of predictive testing because people prefer information, even if it has no bearing on subsequent treatment.(Asch, Patton, \& Hershey 1990;Baker, Atlas, \& Afendulis 2008;Fryback \& Thornbury 1991;Grosse, Wordsworth, \& Payne 2008) Our study tested this presumption empirically and contributes to the field by employing a multi-faceted experimental design in a large population-based internet survey.

The results suggest that most people prefer to take predictive tests even in the absence of direct treatment consequences -- and that they are willing to pay reasonably large amounts for the opportunity. The results hold across multiple diseases, whether or not the test is perfectly accurate, and for different ex ante probabilities regarding the risk of developing the disease in the future.

Our study thus adds to research indicating that people desire information for its own sake. Researchers have found that people generally prefer to learn their disease status or predisposition for conditions including Alzheimer’s, cancer, cystic fibrosis, and Huntington's disease.(Babul et al. 1993;Bratt et al. 2000;Cairns, Shackley, \& Hundley 1996;Erde, Nadal, \& Scholl 1988;Green et al. 1997;Neumann et al. 2001;Van Bebber et al. 2007) Berwick and Weinstein(Berwick \& Weinstein 1985) found that $44 \%$ of women respondents valued ultrasound in pregnancy for reasons unrelated to treatment. Schwartz and colleagues reported that cancer screening was favored by two-thirds of respondents even in the absence of treatment options.(Schwartz et al. 2004) Studies of prenatal screening have reported that WTP estimates are not very sensitive to whether or not a woman plans to terminate an affected pregnancy.(Donaldson, Shackley, 
Abdalla, \& Miedzybrodzka 1995;Donaldson, Shackley, \& Abdalla 1997;Hammitt \& Zhou 2006;Shackley 1996)

This "value of knowing" seems in part a desire for reassurance that one does not have a particular disease. Studies report, for example, that many persons at low risk of hereditary cancer would seek testing as a means of obtaining reassurance.(Andrykowski et al. 1997)

However, it also suggests a desire for information even in the face of possible bad news. Research has demonstrated that people dislike ambiguous situations (in which the probabilities of different outcomes are unknown or uncertain) (Shogren 2005;Viscusi, Magat, \& Huber 1991) and so may prefer situations in which they have better information, even if negative, about their health or their chances of developing a condition.(Ellsberg 1961) One study of people who had undergone genetic testing to determine their risk for developing Huntington's disease found that those who learned they had a very high likelihood of developing the condition were happier a year after testing than those who had not learned their risk.(Wiggins et al. 1992) A study of Alzheimer's genotype disclosure in asymptomatic adults who had a parent with Alzheimer's disease found that disclosure provided a psychological benefit to those who were negative for a susceptibility gene and caused only transient, modest distress to those with a positive result.(Green et al. 2009) The authors concluded that the data supported disclosing information to people who requested it, despite the frightening nature of the disease and the fact that disclosure has no clear medical benefit. Mushlin et al.(Mushlin et al. 1994a) found that even people receiving positive test results became less anxious upon diagnosis, despite the new knowledge that they had a chronic disease. The psychologist Daniel Gilbert(Gilbert 2009) has observed “people find uncertainty more painful than the things they're uncertain about and people feel worse when something bad might occur than when something bad will occur.” 
Consistent with other research, our study suggests that people also value test information because it might alter their behavior.(Neumann et al. 2001;Payne et al. 2007; Van Bebber, Liang, Phillips, Marshall, Walsh, \& Kulin 2007) Despite being told to assume that there was no way to prevent the disease, many respondents noted that they would seek a second opinion or consult a specialist, perhaps to confirm or refute the test results. However, respondents also valued predictive information because of a host of non-health related reasons, such as spending more time with family and attending to personal finances. Most said they would share the news with their spouse, family members and friends, suggesting possible "spillover" effects, which could be particularly important for genetic testing.(Basu \& Meltzer 2005;Grosse, Wordsworth, \& Payne 2008) Most were not worried about others receiving access to the information.

The inclination to take and pay for testing was particularly strong for the breast and prostate cancer scenarios, which may reflect the heightened dread that cancer evokes relative to other conditions.(Hammitt \& Liu 2004;Sunstein CR 1997) and perhaps a disbelief in our claim in the hypothetical scenario that the cancers could not be prevented. Among those who wanted test information, WTP was highest for the breast cancer scenario, which suggests a particular salience for that condition. Fewer people wanted the Alzheimer's test, which suggests fear of living with the prospect of dementia.(Neumann et al. 2001)Respondents were somewhat more inclined to take and to pay for the perfectly accurate vs. the imperfect test.(Hirth et al. 1999;Neumann et al. 2001)

We also found considerable heterogeneity among respondents. Notably, about a quarter of the sample elected not to take the predictive test, perhaps because of anxiety or confusion about testing and/or concerns about living with the burden of disease.(Benkendorf et al. 1997;Drickamer \& Lachs 1992;Kahn 1997;Maguire et al. 1996;Roberts 2000;Van Bebber, 
Liang, Phillips, Marshall, Walsh, \& Kulin 2007;Welkenhuysen, Evers-Kiebooms, \& Van den 1997;Wroe, Salkovskis, \& Rimes 1998) Generally, women, more educated and older individuals and those with healthier behaviors were less inclined to obtain testing. As expected, WTP increased with disease risk and income, and was higher for the perfect than the imperfect test. WTP was smaller for females and those with higher education, age, and risk score, consistent with some prior studies (Neumann et al., 2001), though the literature on the influence of these variables seems mixed (Frew et al., 2001; Caughey, 2004; Yasunaga, 2006; Raab, 2004; Yasunaga, 2009; Lacour, 2008) .

\subsection{Implications}

Health technology assessment (HTA) agencies worldwide are intensifying their scrutiny of predictive tests by requesting evidence that testing not merely increases accuracy, but also improves patient outcomes and has evidence of cost-effectiveness.(Neumann \& Tunis 2010) Conceivably, predictive testing will reduce some costs -- e.g., decreased anxiety may reduce some subsequent health care utilization,(Esfandyari \& Harewood 2007) -- though in most situations net costs will likely rise.(Baker, Atlas, \& Afendulis 2008)

Our study suggests that HTA organizations might better account for individuals' "value of knowing”.(Lee, Neumann, \& Rizzo 2009) Most cost-effectiveness analyses have not included non-health outcomes or preferences for information.(Asch \& Hershey 1995;Asch, Patton, \& Hershey 1990;Grosse, Wordsworth, \& Payne 2008;Hirth et al. 1999) To be sure, how to incorporate these preferences into cost-effectiveness analyses and into health policies raises challenges. There are also questions about whether and to what extent patients should pay themselves for these non-health outcomes. In addition, we did not directly evaluate the fact that for some respondents, receiving the information might generate disutility. These individuals 
have WTP less than zero and, in theory, would need to be compensated to receive the test and hear its results. For those with $\mathrm{WTP}<0$, conventional analyses would overvalue predictive tests and the relevant question is how much clinical value are people willing to trade in order to accept the disutility of knowing the information.

\subsection{Limitations}

It is well known that results from contingent valuation (CV) surveys are influenced by factors ranging from scenario richness and presentation (e.g., how believable and realistic the scenario is and the sequence in which items are presented) to the payment vehicle, expression of risk, time period of valuation, and survey administration.(Hanley, Ryan, \& Wright 2003;Smith 2003;Smith 2008) Responses can be insensitive to the scope of the good or project being valued. People tend to state a similar willingness to pay for any given magnitude of risk reduction(Hammitt \& Graham 1999) and tend to exaggerate valuations of the specific intervention that respondents are asked about, relative to interventions that respondents are not asked about.(Cookson 2003;Hanley, Ryan, \& Wright 2003) Some studies have found much higher hypothetical than real WTP.(Hanley, Ryan, \& Wright 2003)

Our study has a number of limitations, including standard concerns about the hypothetical nature of the vignettes and possible framing effects. We did not include detail on the nature of the test, such as waiting time for results, for example.(Grosse, Wordsworth, \& Payne 2008) Studies have found that patients' acceptance of a test can depend on a test's duration and unpleasantness, and the anxiety resulting from extended waiting times.(Schonenberger et al. 2007;Swan et al. 2000)

Conceivably, some respondents might have been confused by the wording of the questionnaire. For example, some subjects may have believed that the test would help them 
obtain those treatments in a timely fashion - as perhaps suggested by the fact that the most common responses to the information were to seek second opinions and specialty care (59\% each). In addition, it is possible that the estimated WTP did not differ much between respondents told that the test was perfectly accurate and those that were told it was imperfect because respondents discounted the assumption of perfect accuracy. That is, respondents familiar with existing tests might know that no predictive test (other than perhaps for Huntington disease) is close to perfect and thus might reasonably ignore or heavily discount that piece of information.

\subsection{Future research}

Grosse et al.,(Grosse, Wordsworth, \& Payne 2008) observe that the potential of WTP estimates to inform health care policy has remained largely unfulfilled because of difficulties applying the technique in practice, and that most published CV studies in health care remain experimental in nature.(Grosse, Wordsworth, \& Payne 2008) Still, interest in CV methodology endures because it permits a more comprehensive valuation of health benefits than do QALYs.(Olsen \& Smith 2001) CV requires that people express preferences in the single dimension of money, but it does not restrict the attributes of the intervention over which the respondent may have preferences, e.g., one can incorporate preferences for non-health as well as health attributes of the intervention (Olsen \& Smith 2001) In the case of predictive information, $\mathrm{CV}$ offers a clear potential advantage because of the importance of non-health outcomes, such as the value of knowing. Our study demonstrated face validity in that WTP moved in the expected directions with disease risk, test accuracy, income, and individuals’ risk scores. 
CV research has enjoyed broader acceptance among academic economists and policy makers in environmental and transport economics(Hanley, Ryan, \& Wright 2003;Smith 2003) and the potential remains for its application in health care. The field has been aided by advances in techniques for collecting and analyzing data, including use of the double-bounded dichotomous choice and the use of parametric and semi-parametric approaches to estimating the distribution of WTP.(Hanemann, Loomis, \& Kanninen 1991) To build on the work presented here, future researchers could assess other conditions and scenarios and explore further why people want information(Hanley, Ryan, \& Wright 2003) Our study highlights the fact that the desire for this information can be an important component of value.

\section{ACKNOWLEDGMENTS}

This research was supported by a grant from the InHealth Foundation.

\section{REFERENCES}

Andrykowski, M. A., Lightner, R., Studts, J. L., \& Munn, R. K. 1997, "Hereditary cancer risk notification and testing: how interested is the general population?", J Clin Oncol., vol. 15, no. 5, pp. 2139-2148.

Appel, L. J., Steinberg, E. P., Powe, N. R., Anderson, G. F., Dwyer, S. A., \& Faden, R. R. 1990, "Risk reduction from low osmolality contrast media. What do patients think it is worth?", Med.Care, vol. 28, no. 4, pp. 324-337.

Asch, D. A. \& Hershey, J. C. 1995, "Why some health policies don't make sense at the bedside", Ann Intern Med., vol. 122, no. 11, pp. 846-850.

Asch, D. A., Patton, J. P., \& Hershey, J. C. 1990, "Knowing for the sake of knowing: the value of prognostic information", Med Decis.Making, vol. 10, no. 1, pp. 47-57.

Babul, R., Adam, S., Kremer, B., Dufrasne, S., Wiggins, S., Huggins, M., Theilmann, J., Bloch, M., \& Hayden, M. R. 1993, "Attitudes toward direct predictive testing for the Huntington disease gene. Relevance for other adult-onset disorders. The Canadian Collaborative Group on Predictive Testing for Huntington Disease", JAMA., vol. 270, no. 19, pp. 2321-2325. 
Baker, L. C., Atlas, S. W., \& Afendulis, C. C. 2008, "Expanded use of imaging technology and the challenge of measuring value", Health Aff (Millwood)., vol. 27, no. 6, pp. 1467-1478.

Basu, A. \& Meltzer, D. 2005, "Implications of spillover effects within the family for medical cost-effectiveness analysis", J Health Econ., vol. 24, no. 4, pp. 751-773.

Benkendorf, J. L., Reutenauer, J. E., Hughes, C. A., Eads, N., Willison, J., Powers, M., \& Lerman, C. 1997, "Patients' attitudes about autonomy and confidentiality in genetic testing for breast-ovarian cancer susceptibility", Am J Med Genet., vol. 73, no. 3, pp. 296-303.

Berwick, D. M. \& Weinstein, M. C. 1985, "What do patients value? Willingness to pay for ultrasound in normal pregnancy", Med Care, vol. 23, no. 7, pp. 881-893.

Blackmore, C. C., Black, W. C., Jarvik, J. G., \& Langlotz, C. P. 1999, "A critical synopsis of the diagnostic and screening radiology outcomes literature", Acad.Radiol, vol. 6 Suppl 1, pp. S8-18.

Blumenschein, K. \& Johannesson, M. 1999, "Use of contingent valuation to place a monetary value on pharmacy services: an overview and review of the literature", Clin.Ther., vol. 21, no. 8, pp. 1402-1417.

Bossuyt, X., Verweire, K., \& Blanckaert, N. 2007, "Laboratory medicine: challenges and opportunities", Clin.Chem., vol. 53, no. 10, pp. 1730-1733.

Bratt, O., Damber, J. E., Emanuelsson, M., Kristoffersson, U., Lundgren, R., Olsson, H., \& Gronberg, H. 2000, "Risk perception, screening practice and interest in genetic testing among unaffected men in families with hereditary prostate cancer", Eur J Cancer., vol. 36, no. 2, pp. 235-241.

Brooks, S., Cicuttini, F. M., Lim, S., Taylor, D., Stuckey, S. L., \& Wluka, A. E. 2005, "Cost effectiveness of adding magnetic resonance imaging to the usual management of suspected scaphoid fractures", Br.J Sports Med., vol. 39, no. 2, pp. 75-79.

Cairns, J., Shackley, P., \& Hundley, V. 1996, "Decision making with respect to diagnostic testing: a method of valuing the benefits of antenatal screening", Med Decis.Making., vol. 16, no. 2, pp. 161-168.

Carlos, R. C., Hussain, H. K., Song, J. H., \& Francis, I. R. 2002, "Gadolinium-ethoxybenzyldiethylenetriamine pentaacetic acid as an intrabiliary contrast agent: preliminary assessment", AJR Am.J Roentgenol., vol. 179, no. 1, pp. 87-92.

Caughey, A. B., Washington, A. E., Gildengorin, V., \& Kuppermann, M. 2004, "Assessment of demand for prenatal diagnostic testing using willingness to pay", Obstet.Gynecol., vol. 103, no. 3, pp. 539-545.

Chan, S. 2002, "The importance of strategy for the evolving field of radiology", Radiology, vol. 224, no. 3, pp. 639-648. 
Cho, M., Lertmaharit, S., Kamol-Ratanakul, P., \& Saul, A. J. 2000, "Ex post and ex ante willingness to pay (WTP) for the ICT Malaria Pf/Pv test kit in Myanmar", Southeast Asian J Trop.Med.Public Health, vol. 31, no. 1, pp. 104-111.

Cooke, P. 2002, "Biotechnology Clusters as Regional, Sectoral Innovation Systems", International Regional Science Review, vol. 25, no. 1, pp. 8-37.

Cookson, R. 2003, "Willingness to pay methods in health care: a sceptical view", Health Econ., vol. 12, no. 11, pp. 891-894.

Diener, A., O'Brien, B., \& Gafni, A. 1998, "Health care contingent valuation studies: a review and classification of the literature", Health Econ., vol. 7, no. 4, pp. 313-326.

Donaldson, C., Shackley, P., \& Abdalla, M. 1997, "Using willingness to pay to value close substitutes: carrier screening for cystic fibrosis revisited", Health Econ., vol. 6, no. 2, pp. 145159.

Donaldson, C., Shackley, P., Abdalla, M., \& Miedzybrodzka, Z. 1995, "Willingness to pay for antenatal carrier screening for cystic fibrosis", Health Econ., vol. 4, no. 6, pp. 439-452.

Drickamer, M. A. \& Lachs, M. S. 1992, "Should patients with Alzheimer's disease be told their diagnosis?", $N$ Engl J Med., vol. 326, no. 14, pp. 947-951.

Ellsberg, D. 1961, "Risk, ambiguity, and the Savage axioms", Quarterly Journal of Economics, vol. 75, pp. 643-669.

Erde, E. L., Nadal, E. C., \& Scholl, T. O. 1988, "On truth telling and the diagnosis of Alzheimer's disease", J Fam Pract., vol. 26, no. 4, pp. 401-406.

Esfandyari, T. \& Harewood, G. C. 2007, "Value of a negative colonoscopy in patients with nonspecific gastrointestinal symptoms", J Gastroenterol.Hepatol., vol. 22, no. 10, pp. 1609-1614.

Fauli, S. \& Thue, G. 2008, "Economic consequences of near-patient test results: the case of tests for the Helicobacter Pylori bacterium in dyspepsia", Eur.J Health Econ, vol. 9, no. 3, pp. 221228.

Frew, E., Wolstenholme, J. L., \& Whynes, D. K. 2001, "Willingness-to-pay for colorectal cancer screening", Eur.J Cancer, vol. 37, no. 14, pp. 1746-1751.

Fryback, D. G. \& Thornbury, J. R. 1991, "The efficacy of diagnostic imaging", Med Decis.Making., vol. 11, no. 2, pp. 88-94.

Gilbert, D. What you don't know makes you nervous. The New York Times . 5-20-2009.

Ref Type: Newspaper

Green, R. C., Clarke, V. C., Thompson, N. J., Woodard, J. L., \& Letz, R. 1997, "Early detection of Alzheimer disease: methods, markers, and misgivings", Alzheimer Dis.Assoc.Disord., vol. 11 Suppl 5:S1-5; discussion S37-9., p. S1-S5. 
Green, R. C., Roberts, J. S., Cupples, L. A., Relkin, N. R., Whitehouse, P. J., Brown, T., Eckert, S. L., Butson, M., Sadovnick, A. D., Quaid, K. A., Chen, C., Cook-Deegan, R., \& Farrer, L. A. 2009, "Disclosure of APOE genotype for risk of Alzheimer's disease", $N$ Engl J Med., vol. 361, no. 3, pp. 245-254.

Grosse, S. D., Wordsworth, S., \& Payne, K. 2008, "Economic methods for valuing the outcomes of genetic testing: beyond cost-effectiveness analysis", Genet Med., vol. 10, no. 9, pp. 648-654.

Gyrd-Hansen, N. \& Rasmussen, F. 1972, "[The stability of iodophors]", Nord.Vet.Med., vol. 24, no. 12, pp. 612-619.

Hammitt, J. K. \& Graham, J. 1999, "Willingness to Pay for Health Protection: Inadequate Sensitivity to Probability?", Journal of Risk and Uncertainty, vol. 18, no. 1, pp. 33-62.

Hammitt, J. K. \& Liu, J. T. 2004, "Effects of Disease Type and Latency on the Value of Mortality Risk", Journal of Risk and Uncertainty, vol. 28, no. 1, pp. 73-95.

Hammitt, J. K. \& Zhou, Y. 2006, "The Economic Value of Air-Pollution-Related Health Risks in China: A Contingent Valuation Study", Environmental and Resource Economics, vol. 33, no. 3, pp. 399-423.

Hanemann, M., Loomis, J., \& Kanninen, B. 1991, "Statistical Efficiency of Double-Bounded Dichotomous Choice Contingent Valuation", American Journal of Agricultural Economics pp. 1255-1263.

Hanley, N., Ryan, M., \& Wright, R. 2003, "Estimating the monetary value of health care: lessons from environmental economics", Health Econ., vol. 12, no. 1, pp. 3-16.

Hillman, B. J., Amis, E. S., Weinreb, J. C., \& Neiman, H. L. 2005, "The future of imaging screening: proceedings of the Fourth Annual ACR FORUM", J Am Coll.Radiol, vol. 2, no. 1, pp. 43-50.

Hirth, R. A., Bloom, B. S., Chernew, M. E., \& Fendrick, A. M. 1999, "Willingness to pay for diagnostic certainty: comparing patients, physicians, and managed care executives", $J$ Gen.Intern.Med., vol. 14, no. 3, pp. 193-195.

Hirth, R. A., Bloom, B. S., Chernew, M. E., \& Fendrick, A. M. 2000, "Patient, physician, and payer perceptions and misperceptions of willingness to pay for diagnostic certainty", Int.J Technol.Assess.Health Care, vol. 16, no. 1, pp. 35-49.

Iglehart, J. K. 2006, "The new era of medical imaging--progress and pitfalls", N.Engl.J.Med., vol. 354, no. 26, pp. 2822-2828.

J.Michael Dennis 2010, KnowledgePanel: Processes \& Procedures Contributing to Sample Representativeness \& Tests for Self-Selection Bias.

Kahn, J. 1997, "Ethical issues in genetic testing for Alzheimer's disease", Geriatrics., vol. 52 Suppl 2:S30-2., p. S30-S32. 
Kenen, R. H. 1996, "The at-risk health status and technology: a diagnostic invitation and the 'gift' of knowing", Soc Sci Med, vol. 42, no. 11, pp. 1545-1553.

Knechtges, P. M. \& Carlos, R. C. 2007, "The evolving role of radiologists within the health care system", J Am Coll.Radiol, vol. 4, no. 9, pp. 626-635.

Kolata, G. \$300 to Learn Risk of Prostate Cancer. The New York Times . 1-17-2008.

Ref Type: Newspaper

Lachaine, J. 2006, "Therapeutic options for the prevention and treatment of postoperative nausea and vomiting: a pharmacoeconomic review", Pharmacoeconomics., vol. 24, no. 10, pp. 955-970.

Lata, P. F., Binkley, N. C., \& Elliott, M. E. 2002, "Acceptability of pharmacy-based bone density measurement by women and primary healthcare providers", Menopause., vol. 9, no. 6, pp. 449455.

Lee, D. W., Neumann, P. J., \& Rizzo, J. A. 2009, "Understanding the Medical and Nonmedical Value of Diagnostic Testing", Value Health.

Liang, W., Lawrence, W. F., Burnett, C. B., Hwang, Y. T., Freedman, M., Trock, B. J., Mandelblatt, J. S., \& Lippman, M. E. 2003, "Acceptability of diagnostic tests for breast cancer", Breast Cancer Res.Treat., vol. 79, no. 2, pp. 199-206.

Maguire, C. P., Kirby, M., Coen, R., Coakley, D., Lawlor, B. A., \& O'Neill, D. 1996, "Family members' attitudes toward telling the patient with Alzheimer's disease their diagnosis", $B M J$., vol. 313, no. 7056, pp. 529-530.

Maitino, A. J., Levin, D. C., Parker, L., Rao, V. M., \& Sunshine, J. H. 2003, "Nationwide trends in rates of utilization of noninvasive diagnostic imaging among the Medicare population between 1993 and 1999", Radiology, vol. 227, no. 1, pp. 113-117.

Miedzybrodzka, Z., Semper, J., Shackley, P., Abdalla, M., \& Donaldson, C. 1995, "Stepwise or couple antenatal carrier screening for cystic fibrosis?: women's preferences and willingness to pay", J Med.Genet., vol. 32, no. 4, pp. 282-283.

Mushlin, A. I., Kern, L. M., Paris, M., Lambert, D. R., \& Williams, G. 2005, "The value of diagnostic information to patients with chest pain suggestive of coronary artery disease", Med.Decis.Making, vol. 25, no. 2, pp. 149-157.

Mushlin, A. I., Mooney, C., Grow, V., \& Phelps, C. E. 1994b, "The value of diagnostic information to patients with suspected multiple sclerosis. Rochester-Toronto MRI Study Group", Arch.Neurol., vol. 51, no. 1, pp. 67-72.

Mushlin, A. I., Mooney, C., Grow, V., \& Phelps, C. E. 1994a, "The value of diagnostic information to patients with suspected multiple sclerosis. Rochester-Toronto MRI Study Group", Arch.Neurol., vol. 51, no. 1, pp. 67-72. 
National Imaging Associates. Welcome to the National Imaging Associates Web site! www.radmd.com . 2008. 1-15-2008.

Ref Type: Electronic Citation

Neumann, P. J., Hammitt, J. K., Mueller, C., Fillit, H. M., Hill, J., Tetteh, N. A., \& Kosik, K. S. 2001, "Public attitudes about genetic testing for Alzheimer's disease", Health Aff.(Millwood.), vol. 20, no. 5, pp. 252-264.

Neumann, P. J. \& Tunis, S. R. 2010, "Medicare and medical technology--the growing demand for relevant outcomes", $N$ Engl J Med., vol. 362, no. 5, pp. 377-379.

Olsen, J. A. \& Smith, R. D. 2001, "Theory versus practice: a review of 'willingness-to-pay' in health and health care", Health Econ., vol. 10, no. 1, pp. 39-52.

Papatheofanis, F. J. 1998, "Willingness to Pay for Positron Imaging for Diagnostic Evaluation of Suspected Lung Cancer", Clin.Positron.Imaging, vol. 1, no. 4, p. 242.

Papatheofanis, F. J. 2000, "The willingness to pay for positron emission tomography (PET): evaluation of suspected lung cancer using contingent valuation", Q.J Nucl.Med., vol. 44, no. 2, pp. 191-196.

Payne, K., Nicholls, S. G., McAllister, M., MacLeod, R., Ellis, I., Donnai, D., \& Davies, L. M. 2007, "Outcome measures for clinical genetics services: a comparison of genetics healthcare professionals and patients' views", Health Policy., vol. 84, no. 1, pp. 112-122.

Phillips, K. A., Van, B. S., Marshall, D., Walsh, J., \& Thabane, L. 2006, "A review of studies examining stated preferences for cancer screening", Prev.Chronic.Dis., vol. 3, no. 3, p. A75.

PricewaterhouseCoopers 2006, The Factors Fueling Rising Healthcare Costs.

Raab, S. S., Grzybicki, D. M., Hart, A. R., Kiely, S., Andrew-Jaja, C., \& Scioscia E Jr 2002, "Willingness to pay for new Papanicolaou test technologies", Am.J Clin.Pathol., vol. 117, no. 4, pp. 524-533.

Roberts, J. S. 2000, "Anticipating response to predictive genetic testing for Alzheimer's disease: a survey of first-degree relatives", Gerontologist., vol. 40, no. 1, pp. 43-52.

Rodriguez-Monguio, R., Otero, M. J., \& Rovira, J. 2003, "Assessing the economic impact of adverse drug effects", Pharmacoeconomics., vol. 21, no. 9, pp. 623-650.

Ryan, M., Diack, J., Watson, V., \& Smith, N. 2005, "Rapid prenatal diagnostic testing for Down syndrome only or longer wait for full karyotype: the views of pregnant women", Prenat.Diagn., vol. 25, no. 13, pp. 1206-1211.

Sach, T. H., Smith, R. D., \& Whynes, D. K. 2007, "A 'league table' of contingent valuation results for pharmaceutical interventions: a hard pill to swallow?", Pharmacoeconomics., vol. 25, no. 2, pp. 107-127. 
Salkeld, G., Solomon, M., Short, L., Ryan, M., \& Ward, J. E. 2003, "Evidence-based consumer choice: a case study in colorectal cancer screening", Aust.N.Z.J Public Health, vol. 27, no. 4, pp. 449-455.

Schiffner, R., Wilde, O., Schiffner-Rohe, J., \& Stolz, W. 2003, "Difference between real and perceived power of dermoscopical methods for detection of malignant melanoma", Eur.J Dermatol., vol. 13, no. 3, pp. 288-293.

Schonenberger, E., Schnapauff, D., Teige, F., Laule, M., Hamm, B., \& Dewey, M. 2007, "Patient acceptance of noninvasive and invasive coronary angiography", PLoS.ONE., vol. 2, no. 2, p. e246.

Schwartz, L. M., Woloshin, S., Fowler, F. J., Jr., \& Welch, H. G. 2004, "Enthusiasm for cancer screening in the United States", JAMA, vol. 291, no. 1, pp. 71-78.

Seshadri, S. 2005, "Why advances in imaging technology are good for radiology, patients, and the bottom line", J Am Coll.Radiol, vol. 2, no. 1, pp. 5-7.

Shackley, P. 1996, "Economic evaluation of prenatal diagnosis: a methodological review", Prenat.Diagn., vol. 16, no. 5, pp. 389-395.

Shih, H. C., Chou, P., Chen, S. J., Liu, J. H., Lee, F. L., Liu, C. M., \& Tung, T. H. 2007, "A community-based study of the willingness to pay associated with screening for diabetic retinopathy among type 2 diabetes in Kinmen, Taiwan", J Epidemiol., vol. 17, no. 6, pp. 186193.

Shogren, J. 2005, Economics of diet and health: research challenges Section C, 2.

Singer, M. E. \& Applegate, K. E. 2001, "Cost-effectiveness analysis in radiology", Radiology, vol. 219, no. 3, pp. 611-620.

Smith, R. D. 2003, "Construction of the contingent valuation market in health care: a critical assessment", Health Econ., vol. 12, no. 8, pp. 609-628.

Smith, R. D. 2008, "Contingent valuation in health care: does it matter how the 'good' is described?", Health Econ., vol. 17, no. 5, pp. 607-617.

Sunstein CR 1997, "Bad Deaths", J Risk Uncert, vol. 14, pp. 259-282.

Swan, J. S., Fryback, D. G., Lawrence, W. F., Sainfort, F., Hagenauer, M. E., \& Heisey, D. M. 2000, "A time-tradeoff method for cost-effectiveness models applied to radiology", Med Decis.Making, vol. 20, no. 1, pp. 79-88.

Tarasiuk, A., Simon, T., Regev, U., \& Reuveni, H. 2003, "Willingness to pay for polysomnography in children with obstructive sleep apnea syndrome: a cost-benefit analysis", Sleep, vol. 26, no. 8, pp. 1016-1021. 
Tufts Medical Center. Cost-Effectiveness Analysis Registry. http://www.cearegistry.org . 2010. Ref Type: Electronic Citation

Van Bebber, S., Liang, S., Phillips, K., Marshall, D., Walsh, J., \& Kulin, N. 2007, "Valuing personalized medicine: Willingness to pay for genetic testing for colorectal cancer risk", Personal Med., vol. 4, pp. 341-350.

Viscusi, W., Magat, W., \& Huber, J. 1991, "Communication of ambiguous risk information", Theory and Decision, vol. 31, pp. 159-173.

Wagner, T. H., Hu, T., Duenas, G. V., Kaplan, C. P., Nguyen, B. H., \& Pasick, R. J. 2001, "Does willingness to pay vary by race/ethnicity? An analysis using mammography among low-income women", Health Policy, vol. 58, no. 3, pp. 275-288.

Weinstein, M. C., Fineberg, H. V., Elstein AS, Frazier HS, Neuhauser D, Neutra RR, \& McNeil, B. J. 1980, Clinical Decision Analysis W.B. Saunders, Philadelphia.

Weinstein, M. C., Siegel, J. E., Gold, M. R., Kamlet, M. S., \& Russell, L. B. 1996, "Recommendations of the Panel on Cost-effectiveness in Health and Medicine", Jama, vol. 276, no. 15, pp. 1253-8.

Welkenhuysen, M., Evers-Kiebooms, G., \& Van den, B. H. 1997, "Attitudes toward predictive testing for Alzheimer's disease in a student population", Psychiatr.Genet., vol. 7, no. 3, pp. 121126.

Whynes, D. K., Frew, E., \& Wolstenholme, J. L. 2003, "A comparison of two methods for eliciting contingent valuations of colorectal cancer screening", J Health Econ, vol. 22, no. 4, pp. 555-574.

Wiggins, S., Whyte, P., Huggins, M., Adam, S., Theilmann, J., Bloch, M., Sheps, S. B., Schechter, M. T., \& Hayden, M. R. 1992, "The psychological consequences of predictive testing for Huntington's disease. Canadian Collaborative Study of Predictive Testing", $N$ Engl J Med., vol. 327, no. 20, pp. 1401-1405.

Wordsworth, S., Ryan, M., \& Waugh, N. 2001, "Costs and benefits of cervical screening IV: valuation by women of the cervical screening programme", Cytopathology, vol. 12, no. 6, pp. 367-376.

Wroe, A. L., Salkovskis, P. M., \& Rimes, K. A. 1998, "The prospect of predictive testing for personal risk: attitudes and decision making", Behav.Res Ther., vol. 36, no. 6, pp. 599-619.

Yasunaga, H. 2008, "Willingness to pay for mass screening for prostate cancer: a contingent valuation survey", Int.J Urol., vol. 15, no. 1, pp. 102-105.

Yasunaga, H., Ide, H., Imamura, T., \& Ohe, K. 2006a, "Benefit evaluation of mass screening for prostate cancer: willingness-to-pay measurement using contingent valuation", Urology, vol. 68, no. 5, pp. 1046-1050. 
Yasunaga, H., Ide, H., Imamura, T., \& Ohe, K. 2006b, "The measurement of willingness to pay for mass cancer screening with whole-body PET (positron emission tomography)", Ann.Nucl.Med., vol. 20, no. 7, pp. 457-462.

Yasunaga, H., Ide, H., Imamura, T., \& Ohe, K. 2007, "Women's anxieties caused by false positives in mammography screening: a contingent valuation survey", Breast Cancer Res.Treat., vol. 101, no. 1, pp. 59-64. 
Table 1: Sample statistics

\begin{tabular}{|c|c|c|c|c|c|}
\hline Gender & \multicolumn{5}{|c|}{ Male (51\%) } \\
\hline Age (Mean \pm SD) & \multicolumn{5}{|c|}{$43( \pm 16.2)$} \\
\hline \multicolumn{6}{|l|}{ Education } \\
\hline Less than High School & \multicolumn{5}{|c|}{$11 \%$} \\
\hline High School & \multicolumn{5}{|c|}{$30 \%$} \\
\hline Some College & \multicolumn{5}{|c|}{$29 \%$} \\
\hline Bachelor's degree or higher & \multicolumn{5}{|c|}{$31 \%$} \\
\hline \multicolumn{6}{|l|}{ Household Income (annual) } \\
\hline Less than $\$ 20,000$ & \multicolumn{5}{|c|}{$14 \%$} \\
\hline$\$ 20,000$ to 39,999 & \multicolumn{5}{|c|}{$23 \%$} \\
\hline$\$ 40,000$ to 59,999 & \multicolumn{5}{|c|}{$18 \%$} \\
\hline$\$ 60,000$ to 84,999 & \multicolumn{5}{|c|}{$21 \%$} \\
\hline More than $\$ 85,000$ & \multicolumn{5}{|c|}{$25 \%$} \\
\hline \multirow[t]{2}{*}{ Risk Score* (Mean \pm SD) } & \multicolumn{5}{|c|}{$11 \pm(4.0)$ (95\% range: $5-18)$} \\
\hline & Always & Usually & Sometimes & Rarely & Never \\
\hline Wear seatbelt & $83 \%$ & $9 \%$ & $4 \%$ & $2 \%$ & $1 \%$ \\
\hline Eat healthy diet & $15 \%$ & $47 \%$ & $31 \%$ & $6 \%$ & $1 \%$ \\
\hline Annual check-up & $39 \%$ & $18 \%$ & $16 \%$ & $15 \%$ & $12 \%$ \\
\hline Smoke & $44 \%$ & $12 \%$ & $20 \%$ & $7 \%$ & $16 \%$ \\
\hline Exercise regularly & $56 \%$ (Yes) & & & & \\
\hline
\end{tabular}

*The Risk Score is an aggregation of responses to questions indicative of respondent risk tolerance. Its value is the sum of points awarded based on responses to each of five questions. For each question, a higher point score indicates greater tolerance of risk, or engagement in more risky behaviors. For example, we ask respondents whether they wear a seatbelt always (1 point), usually (2 points), sometimes ( 3 points), rarely (4 points), or never ( 5 points). Other questions ask about diet, how often the respondent gets an annual checkup, smoking, and exercise. For regular exercise question, we only have yes (1 point) and No (5 points). 
Table 2. Proportion of respondents who would take the test and willingness to pay for all respondents ${ }^{(a)}$

\begin{tabular}{|c|c|c|c|c|}
\hline & \multicolumn{2}{|c|}{ Disease Risk 10\% } & \multicolumn{2}{|c|}{ Disease Risk 25\% } \\
\hline $\mathrm{P}^{2}$ & Perfect & Imperfect & Perfect & Imperfect \\
\hline Alzheimer's Disease & & & & \\
\hline $\begin{array}{l}\text { Pct who would take test }{ }^{(a)} \\
\text { Median - all respondents }{ }^{(a)} \\
\text { Mean - all respondents }{ }^{(a)}\end{array}$ & $\begin{array}{l}74.0 \% \\
\$ 153 \\
\$ 479 \\
\end{array}$ & $\begin{array}{l}70.4 \% \\
\$ 120 \\
\$ 409 \\
\end{array}$ & $\begin{array}{l}74.8 \% \\
\$ 162 \\
\$ 500 \\
\end{array}$ & $\begin{array}{l}71.2 \% \\
\$ 128 \\
\$ 428 \\
\end{array}$ \\
\hline Arthritis & & & & \\
\hline $\begin{array}{l}\text { Pct who would take test }{ }^{(a)} \\
\text { Median - all respondents }{ }^{(a)} \\
\text { Mean - all respondents }{ }^{(a)}\end{array}$ & $\begin{array}{l}80.2 \% \\
\$ 135 \\
\$ 370\end{array}$ & $\begin{array}{l}77.2 \% \\
\$ 109 \\
\$ 320 \\
\end{array}$ & $\begin{array}{l}80.8 \% \\
\$ 142 \\
\$ 385 \\
\end{array}$ & $\begin{array}{l}77.9 \% \\
\$ 116 \\
\$ 333 \\
\end{array}$ \\
\hline Breast Cancer & & & & \\
\hline $\begin{array}{l}\text { Pct who would take test }{ }^{(a)} \\
\text { Median - all respondents }{ }^{(a)} \\
\text { Mean - all respondents }\end{array}$ & $\begin{array}{l}81.9 \% \\
\$ 221 \\
\$ 587\end{array}$ & $\begin{array}{l}79.0 \% \\
\$ 181 \\
\$ 508\end{array}$ & $\begin{array}{l}82.4 \% \\
\$ 232 \\
\$ 610\end{array}$ & $\begin{array}{l}79.7 \% \\
\$ 191 \\
\$ 529\end{array}$ \\
\hline Prostate Cancer & & & & \\
\hline $\begin{array}{l}\text { Pct who would take test if free }{ }^{(a)} \\
\text { Median - all respondents }{ }^{(a)} \\
\text { Mean - all respondents }\end{array}$ & $\begin{array}{l}87.5 \% \\
\$ 251 \\
\$ 600\end{array}$ & $\begin{array}{l}85.4 \% \\
\$ 212 \\
\$ 526\end{array}$ & $\begin{array}{c}88.0 \% \\
\$ 263 \\
\$ 622\end{array}$ & $\begin{array}{c}85.9 \% \\
\$ 222 \\
\$ 546\end{array}$ \\
\hline
\end{tabular}

Notes:(a) The percentage of respondents who would take the test, includes those who would only take it if it were free, as well as those who were willing to pay for testing. "All respondents" refers to both those who would take the test if it were free and those who would not. The mean reported here reflects the assumption that the test is worth zero to respondents who would not take it even if it were free. The median reported here reflects the assumption that the test is worth no more than zero to this group. 
Table 3. Regression Results

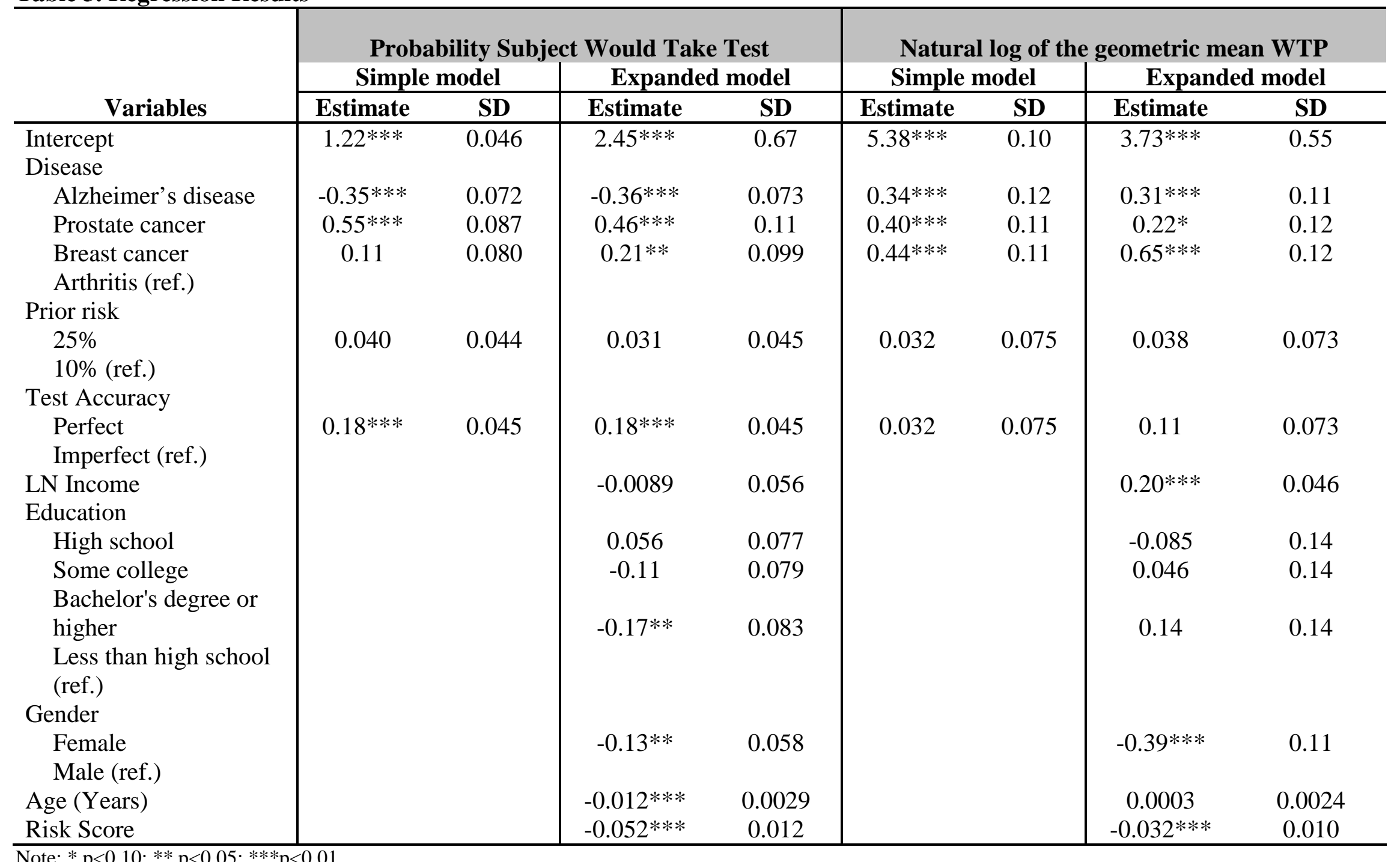




\begin{tabular}{|c|c|c|c|c|c|}
\hline & \multirow[b]{2}{*}{ Overall } & \multicolumn{4}{|c|}{ Disease } \\
\hline & & Alzheimer's & Arthritis & $\begin{array}{l}\text { Prostate } \\
\text { Cancer }\end{array}$ & $\begin{array}{l}\text { Breast } \\
\text { Cancer }\end{array}$ \\
\hline \multicolumn{6}{|l|}{ What would you do with a positive test? } \\
\hline Seek medical care from a medical specialist & $59 \%$ & $50 \%$ & $36 \%$ & $61 \%$ & $59 \%$ \\
\hline $\begin{array}{l}\text { Sign a document specifying how you want to be } \\
\text { treated if you became ill }\end{array}$ & $51 \%$ & $53 \%$ & $24 \%$ & $50 \%$ & $53 \%$ \\
\hline Travel more & $31 \%$ & $42 \%$ & $21 \%$ & $28 \%$ & $33 \%$ \\
\hline Seek help from a mental health professional & $27 \%$ & $37 \%$ & $6 \%$ & $23 \%$ & $31 \%$ \\
\hline Change jobs & $7 \%$ & $3 \%$ & $3 \%$ & $6 \%$ & $8 \%$ \\
\hline Quit working/retire & $7 \%$ & $9 \%$ & $7 \%$ & $7 \%$ & $6 \%$ \\
\hline \multicolumn{6}{|l|}{ Who would you tell? ${ }^{2}$} \\
\hline Minister/rabbi/clergy member & $34 \%$ & $25 \%$ & $31 \%$ & $36 \%$ & $33 \%$ \\
\hline Co-workers & $22 \%$ & $10 \%$ & $32 \%$ & $23 \%$ & $22 \%$ \\
\hline \multicolumn{6}{|l|}{ How worried are you about people gaining access? ${ }^{3}$} \\
\hline Insurance company & $37 \%$ & $45 \%$ & $38 \%$ & $37 \%$ & $37 \%$ \\
\hline The government & $28 \%$ & $34 \%$ & $17 \%$ & $28 \%$ & $27 \%$ \\
\hline Employer & $24 \%$ & $28 \%$ & $27 \%$ & $23 \%$ & $24 \%$ \\
\hline
\end{tabular}

Note: The table excludes individuals who were "not applicable" respondents (e.g., those who were not employed were excluded from the question about how worried they would be that their employer would gain access to test information).

1. Includes those responding "Very likely" or "Somewhat likely"

2. Includes those responding "Definitely would tell" or "Probably would tell"

3. Respondents were asked whether they were "worried" or "not worried" 


\section{Table Legends:}

\section{Table 1:}

Characteristics of the survey sample

\section{Table 2:}

Proportion of respondents who would take the test and willingness to pay for all respondents

\section{Table 3:}

Results of the 2-part regression model

\section{Table 4:}

Survey respondent attitudes about testing 


\section{Figure 1: Sample Scenario}

Imagine that you go to the doctor for your regular check up. Your doctor tells you that you are healthy but that someone your age has a 25\% chance of some day getting Alzheimer's disease. The people in red represent the number out of 100 that might get Alzheimer's disease.

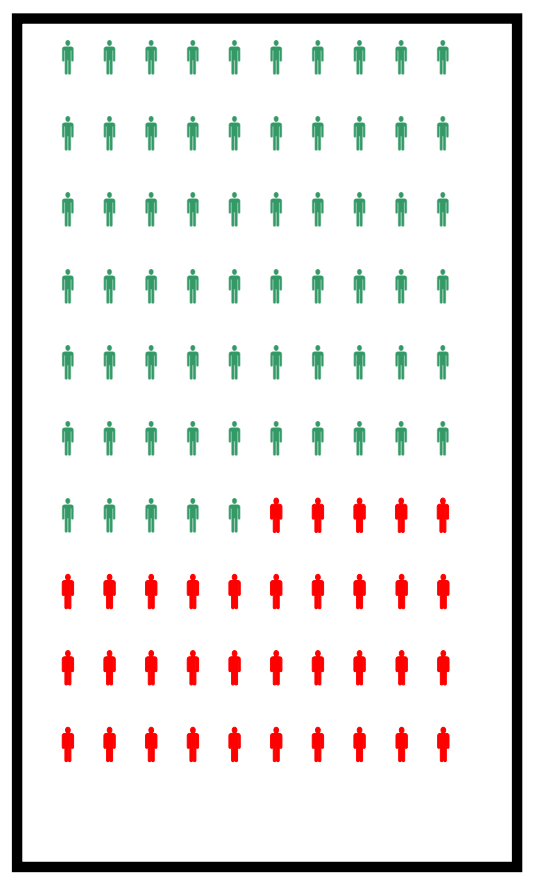

As you may know, Alzheimer's disease is a disease of memory that worsens over time. Most people who get Alzheimer's disease are over age 65.

The doctor tells you that a new blood test is available that will tell you now whether or not you will one day develop Alzheimer's disease. The test is $100 \%$ accurate. You will have to pay for the test yourself because insurance does not pay for it.

Assume for this scenario that you cannot prevent the disease from occurring. For people who get the disease, there are treatments available that may help.

Would you want to take the test if it cost you $\$ 50 ?$ 
Figure 2: Survey Design

Willingness to Pay

\begin{tabular}{lcccc}
\hline Disease Risk & $25 \%$ & $10 \%$ & $25 \%$ & $10 \%$ \\
\hline Test Accuracy & Perfect & Perfect & Imperfect & Imperfect \\
\hline Disease & & & & \\
$\begin{array}{l}\text { Alzheimer's } \\
\text { Disease }\end{array}$ & 193 & 193 & 193 & 193 \\
$\begin{array}{l}\text { Arthritis } \\
\text { Prostate Cancer }\end{array}$ & 192 & 189 & 190 & 191 \\
& 169 & 186 & 159 & 184 \\
Breast Cancer & 166 & 165 & 165 & 208
\end{tabular}

Note: 1,463 respondents were randomized to answer questions about two of 16 scenarios each of which contained one of four diseases (Alzheimer's disease, arthritis, breast cancer or prostate cancer), a disease risk (10\% or $25 \%$ ) and information about test accuracy (perfect test, "not perfectly accurate"). The figure shows the sample allocated to each of the 16 scenarios. 